\title{
Five new chironomid species of five genera from Japan
}

\author{
Koichiro KawaI, Hideaki Okamoto and Hiromichi Imabayashi \\ Laboratory of Ecology, Faculty of Applied Biological Sciense, Hiroshima University, 4-4, \\ Kagamiyama 1-chome, Higashihiroshima-shi, Hiroshima, 739-8528 Japan
}

(Received: 3 October, 2001; Accepted: 22 March, 2002)

Key words: adult male, chironomid, description, morphology, new genus, new species

\begin{abstract}
Five new species of chironomids from Japan, belonging to 5 genera, including a new genus Amphismittia, and Bryophaenocladius, Harnischia, Polypedilum and Tanytarsus, were described on the basis of morphology of adult males emerging from the bottom samples and collected from the artificial light sources and by sweeping.
\end{abstract}

\section{INTRODUCTION}

Chironomid fauna in Japan was investigated mainly by Dr. M. Tokunaga and his collaborators up to 1965 and about 160 species had been recorded. Thereafter, the fauna was energetically studied mainly by Sasa and his collaborators, and more than 500 species were additionally recorded in a list provided by Sasa and Kikuchi (1995). However, still more work is necessary for complete clarification of the Japanese fauna. In this study, five new species, each belonging to a different genus, were collected and described on the basis of morphology of adult males.

\section{Materials and Methods}

Male adults were collected by three methods: collection of adults emerging from bottom samples, such as stones, sand, mud or waterweeds, collection of adults attracted to artificial illumination emitted by light traps and vending machines, and collection by sweeping.

Mounting of male specimens was performed according to the method described by Sasa et al. (1980). Identification was carried out using the keys provided by
Pinder (1978), Wiederholm (1989) and Sasa and Kikuchi (1995).

Type materials are temporally deposited in the Laboratory of Ecology, Faculty of Applied Biological Science, Hiroshima University, Japan.

The abbreviations in the descriptions of species mean the following measurements and ratios cited from Sasa and Kikuchi (1995), with some modifications.

BL: body length, or the combined length in mm of thorax and abdomen in slide-mounted specimens.

WL: wing length, or the distance between tip of wing and arculus.

$A R$ : antennal ratio, obtained by dividing the length of the last antennal segment with the combined length of the remaining flagellar segments (not including pedicel).

ER: eye ratio, obtained by dividing the distance between dorsomedian corners of two eyes with the height of an eye.

SO: number of supraorbital setae on one side.

CL: number of clypeal setae.

$\mathrm{PN}$ : number of setae on antepronotum on each side.

DM: number of dosromedian setae on scutum. 
A
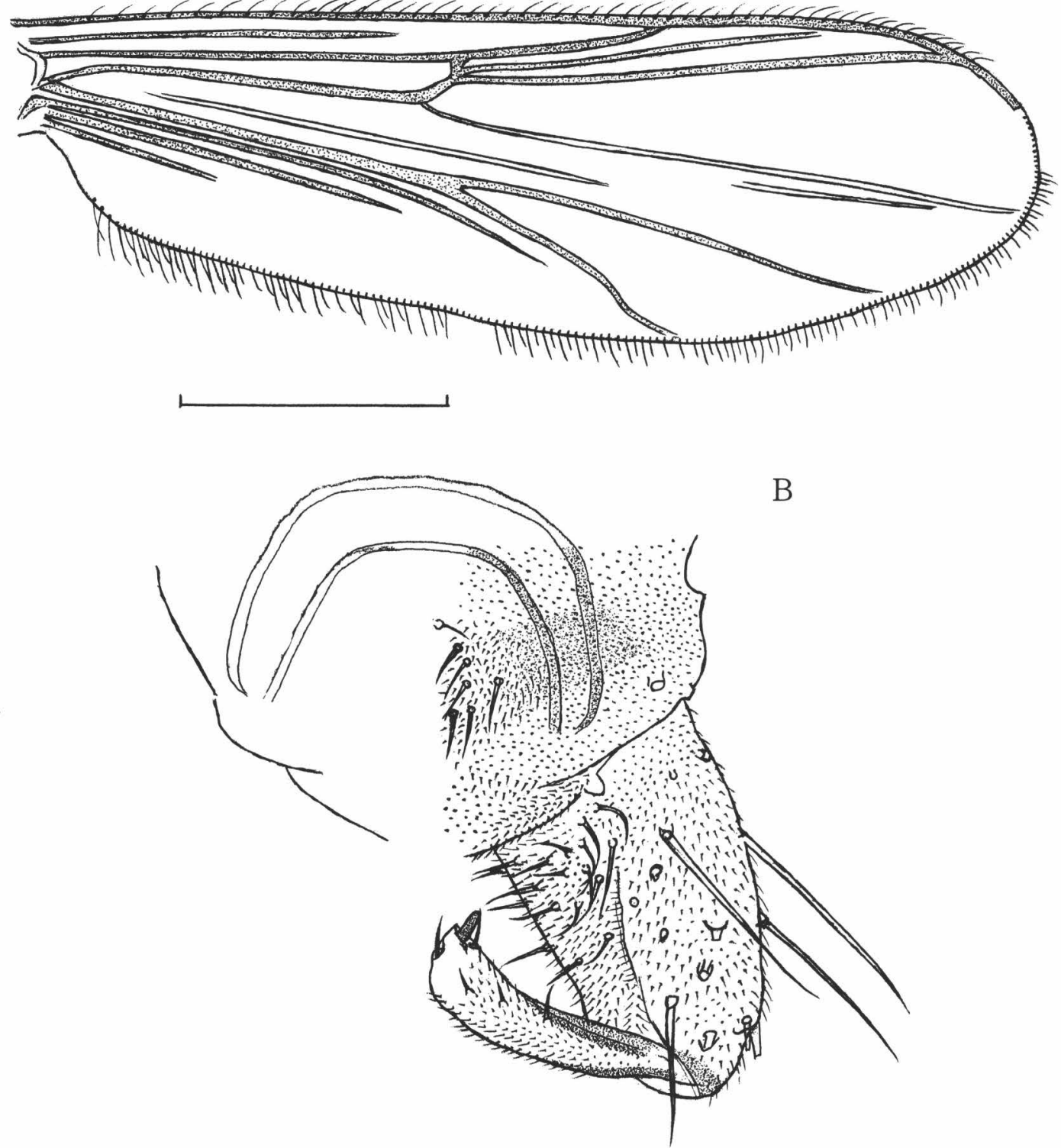

Fig. 1. Amphismittia yoshiwaensis sp. nov. Male. A, wing. Scale: $0.5 \mathrm{~mm}$; B, hypopygium. Scale: $0.1 \mathrm{~mm}$.

DL: number of dorsolateral setae on each side of scutum.

SA: number of supraalar setae on each side of scutum.

PA: number of prealar setae on each side of scutum.

SC: number of setae on scutellum.

SQ: number of fringe setae on squama.
$\mathrm{LR}_{1}$ : front leg ratio, obtained by dividing the length of front tarsal segment I with the length of front tibia.

$L_{2}$ : ratio obtained by dividing the length of middle tarsal segment I with the length of middle tibia.

$L_{2}$ : ratio obtained by dividing the length of hind tarsal segment 
I with the length of hind tibia.

$\mathrm{TR}_{1}$ : ratio obtained by dividing the length of front tarsal segment $\mathrm{V}$ with the length of front tibia.

$\mathrm{BR}_{1}$ : front beard ratio, obtained by dividing the length of the longest hair on front tarsal segment I with the diameter of the segment at the base of the hair.

$\mathrm{BR}_{2}, \mathrm{BR}_{3}$ : same, referring to the beard ratio of middle and hind tarsal segment I.

\section{Description of Adult Males}

\section{Subfamily Orthocladiinae}

\section{Amphismittia gen. nov.}

Type species: Amphismittia yoshiwaensis sp. nov.

Diagnostic characters: Separable from other genera of Orthocladiinae in having completely bare eyes, strong straight subapical seta on antenna, antennal ratio less than 1.0, bare squama, bare wing membrane, strongly extended costa, no anal point and tergite IX not divided into two lobes.

\section{Amphismittia yoshiwaensis sp. nov.}

Male $(n=3)$

Coloration (in specimen mounted in gum-chloral): Head reddish-brown. Antennal flagella and plume brown. Palps pale brown. Antepronotum dark brown. Scutum yellowish-brown; scutal stripes indistinguishable. Scutellum and postnotum brown. Halteres transparent. Legs uniformly light brown. Abdomen light brown; each tergite with a dark brown band on oral half. Hypopygium light brown.

Structure: AR 0.64-0.68. SO 7-8. Eyes completely bare with weak dorsomedial projections, ER 0.52. CL 8. PN 2. DM 7-8, starting close to antepronotum. DL 1112. SA 2-4. SC 5. SQ 0 . Wing as in Fig. 1A. Wing membrane granular at $100 \times$ magnificance. Anal lobe slightly developed, with rounded margin. Costa strong- ly extended beyond the end of $R_{4+5} \cdot R_{2+3}$ running separately from both $\mathrm{R}_{1}$ and $\mathrm{R}_{4+5}$ and ending almost midway between the tips of both veins. $\mathrm{R}_{4+5}$ ending slightly distal to the tip of $\mathrm{M}$. FCu well beyond RM. $\mathrm{Cu}_{2}$ slightly curved at the tip. $\mathrm{LR}_{1}$ 0.68-0.72. LR $\mathrm{LR}_{2}$ 0.40-0.46. $\mathrm{LR}_{3}$ 0.480.53. $\mathrm{TR}_{1} 0.10-0.11 . \mathrm{BR}_{1} 1.6-2.3 . \mathrm{BR}_{2} 1.4-$ 2.3. $\mathrm{BR}_{3}$ 1.4-3.1. Front tibia with a long terminal spur. Middle tibia with two terminal spurs; one short and the other longish. Hind tibia with a terminal comb and a long terminal spur. Tarsi without pseudospurs. Pulvilli absent. Hypopygium as in Fig. 1B. Anal point absent. Ninth tergite not divided into two lobes, with about 10 strong bristles along caudomedial margin. Virga absent. Gonocoxite distally tapered with straight inner margin and without any inner lobes. Gonostylus robust, straight and distally swollen and with a well-developed megaseta.

Size: BL 2.21-2.38 mm WL 1.25-1.37 $\mathrm{mm}$.

Type material: Holotype $\sigma^{\top}$ attracted to a light trap set at the shore of the Ohta River, Yoshiwa-Mura, Saeki-Gun, Hiroshima Pref., Japan, on Aug. 21, 1996. Paratypes $2 \sigma^{\nearrow}$ from the same sample as holotype.

Discussion: This new genus Amphismittia seems closely related to Tsudayusurika Sasa in that eyes and squama are bare, wing membrane is granular, vein $\mathrm{Cu}_{2}$ is curved at the tip, costa is extended beyond the tip of $R_{4+5}$ and anal point is absent. However, it is easily distinguishable from the latter in having a strong straight subapical seta on antenna and AR less than 0.7 (see Sasa, 1985). It is also related to Semiocladius Sublette et Wirth and Smittia Holmgren. However, it clearly differs from Semiocladius in having a strong subapical seta on antenna and tergite IX not divided into two lobes, and from Smittia in that eyes are bare, AR is less than 0.7 and anal point is absent (see Wiederholm, 1989). It is somewhat related to Chaetocladius Kieffer, but is quite different from the latter in hav- 

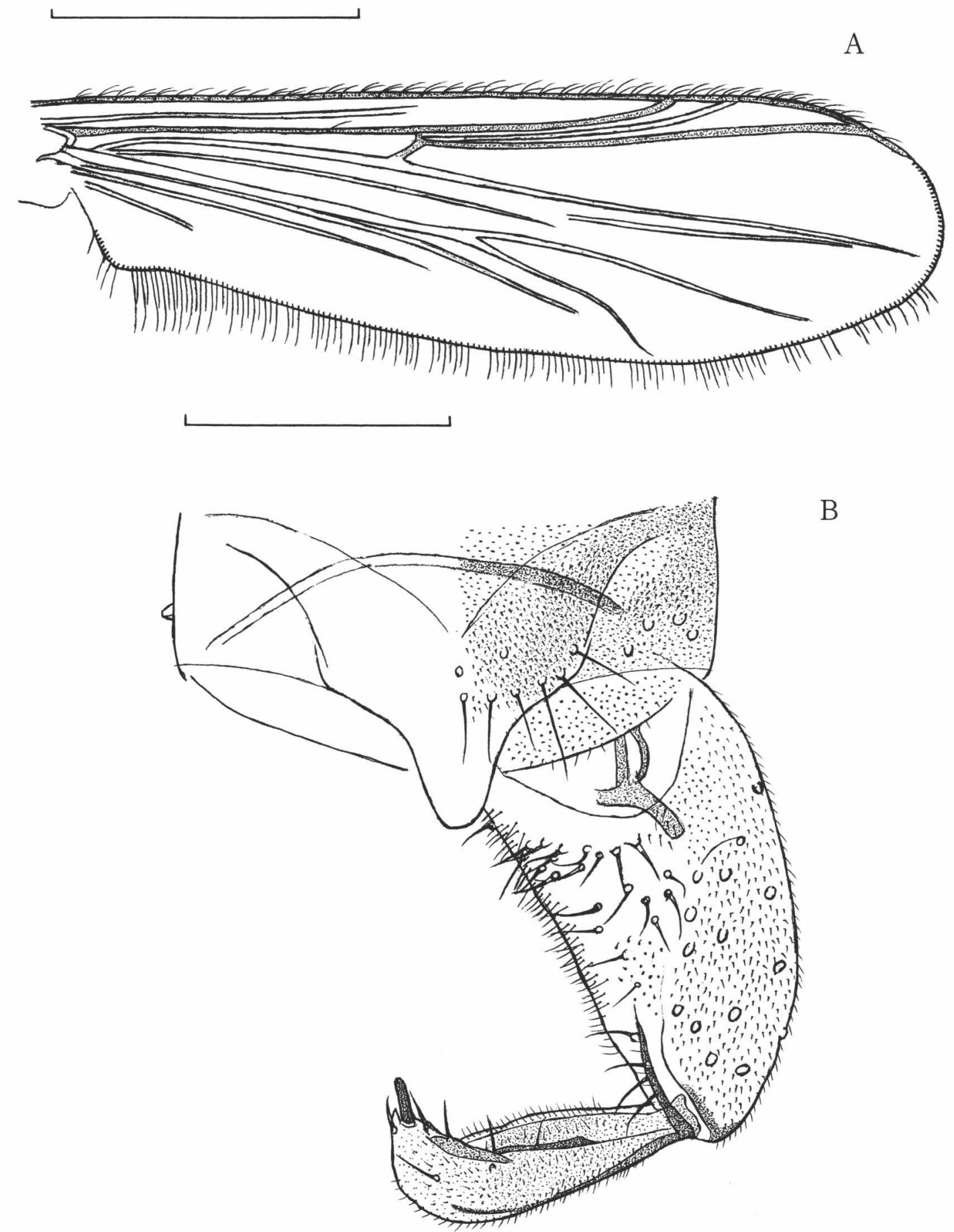

$\mathrm{B}$

Fig. 2. Bryophaenocladius simplicicoxus sp. nov. Male. A, wing. Scale: $0.5 \mathrm{~mm}$; B, hypopygium. Scale: 0.1 $\mathrm{mm}$.

ing completely bare eyes and strongly extended costa (see Pinder, 1978).
Bryophaenocladius simplicicoxus sp. nov. Male $(\mathrm{n}=1)$

Coloration (in specimen mounted in 
gum-chloral): Head, antennal shaft and plume dark brown. Palps pale brown. Scutal ground yellow; scutal stripes brown and distinguishable. Prescutellar area darkened. Scutellum pale brown. Postnotum brown. Halteres pale brown. Legs uniformly brown. Abdomen and hypopygium brown.

Structure: AR 1.26. SO 8. Eyes bare with moderate dorsomedial projections, ER 0.87. PN 5. DM 11, distributed from close to the antepronotum. DL 8-9. SA 5. SC 5. SQ 4. Wing as in Fig. 2A. Wing membrane granular. Anal lobe moderately developed. Costa much produced beyond the tip of $R_{4+5} . \quad R_{2+3}$ running separately from both $R_{1}$ and $R_{4+5}$ and ending almost midway between the tips of $R_{1}$ and $R_{4+5} \cdot R_{4+5}$ ending above the tip of $\mathrm{Cu}_{1}$. FCu well beyond RM. $\mathrm{Cu}_{2}$ strongly curved distally. Front tibia with a long terminal spur. Middle tibia with two long terminal spurs. Hind tibia with 2 terminal spurs; one long and the other shorter, and with a terminal comb. Middle and hind tarsi without pseudosours. Pulvilli vestigial. Hypopygium as in Fig. 2B. Ninth tergite with many strong setae on the caudal margin. Virga absent. Anal point transparent, broad and with rounded apex. Gonocoxite large and distally tapered, and without any inner lobes. Gonostylus stout, distally expanded and strongly curved apically and with a well-developed megaseta.

Size: BL $2.16 \mathrm{~mm}$ WL $1.23 \mathrm{~mm}$.

Type material: Holotype or attracted to a light trap set at the shore of the Ohta River, Yoshiwa-Mura, Saeki-Gun, Hiroshima Pref., Japan, on Aug. 21, 1996.

Discussion: This species should be affiliated to the genus Bryophaenocladius Thienemann because wing membrane is granular, costa extended beyond the tip of $\mathrm{R}_{4+5}$, squama is fringed, $\mathrm{Cu}_{2}$ is curved, dorsomedian setae are distributed from close to the antepronotum, anal point is hyaline and apically rounded, although virga is absent. This is clearly different from all the species described so far in having gonocoxite without any inner lobes (See Pinder, 1978; Sasa and Okazawa, 1992).

\section{Subfamily Chironominae}

Harnischia biwacurtus sp. nov.

Male $(n=3)$

Coloration (in specimen mounted in gum-chloral): Head pale yellow. Pedicel yellowish-brown. Antennal shaft and plume brown. Palps pale brown. Scutal background hyaline. Scutal stripes yellowish-brown, conspicuous. Scutellum pale brown. Postnotum brown; anteriorly pale brownish, posteriorly lighter. Halteres pale yellow. Femora yellowish. Tibiae and tarsi light brownish. Front leg segments darker. Abdomen yellowish-pale brown. Hypopygium brown.

Structure: AR 1.63-2.25. SO 13-17. Eyes with strong dorsomedial projections, ER 0.20-0.33. CL 12-15. PN 2-4. DM 1011. DL 9-13. SA 3. SC 6-7. SQ 5-10. Wing as in Fig. 3A. Wing membrane purplish by transmittent light. Anal lobe well developed, rectanglar. Costa not produced beyond the tip of $R_{4+5} . R_{2+3}$ running separately from both $\mathrm{R}_{1}$ and $\mathrm{R}_{4+5}$ and ending closer to the tip of $\mathrm{R}_{1}, \mathrm{R}_{4+5}$ ending slightly distal to the tip of $\mathrm{Cu}_{1}$. FCu slightly beyond RM. $\mathrm{LR}_{1} 2.22-2.36$. $\mathrm{LR}_{2}$ 0.67-0.74. $\mathrm{LR}_{3}$ 0.80-0.84. TR $\mathrm{TR}_{1}$ 0.270.31. $\mathrm{BR}_{2} 2.0-2.6 . \mathrm{BR}_{3} 2.8-3.4$. Front tibia without terminal spur and with rounded terminal scale. Middle and hind tibia with two terminal combs; each with a spur, one long and the other shorter. Large pulvilli present. Hypopygium as in Fig. 3B. Caudal margin of ninth tergite rounded medially. Anal point long, stout, widest at base and distally tapered with pointed apex. Gonocoxite large, fused with gonostylus. Gonostylus short, straight, distally truncate and slightly expanded and with a hook-like projection at distal end on inner margin. Dorsal appendage vestigial, conical and with 3 strong setae. Ventral appendage absent.

Size: BL 3.19-4.29 mm WL 1.49-1.96 

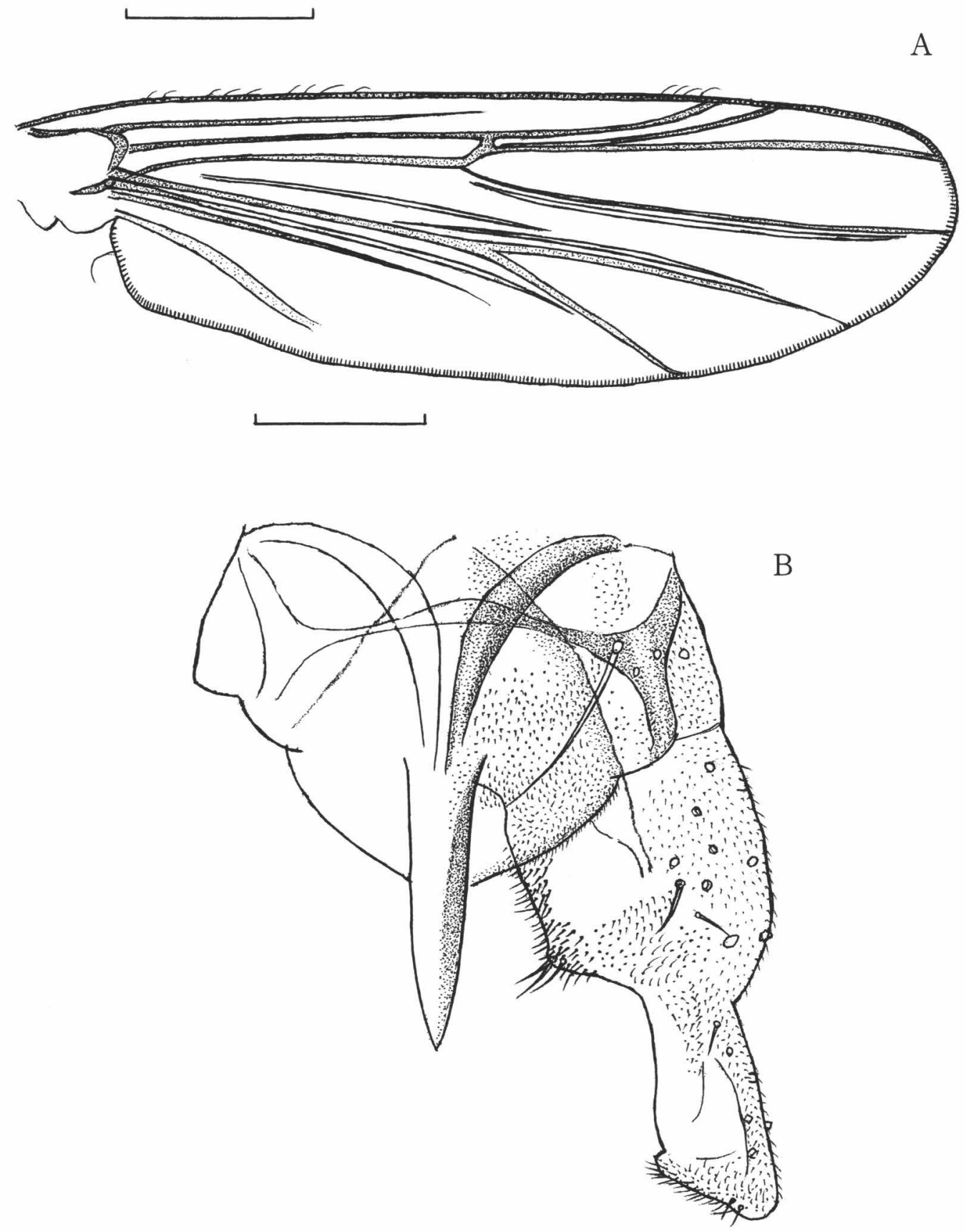

Fig. 3. Harnischia biwacurtus sp. nov. Male. A, wing. Scale: $0.5 \mathrm{~mm}$; B, hypopygium. Scale: $0.1 \mathrm{~mm}$.

$\mathrm{mm}$.

Type material: Holotype $\sigma^{7}$ attracted to a light source emitted by a vending machine set at the shore of Lake Biwa, Kitakomatsu, Shiga-Cho, Shiga-Gun, Shiga Pref., Japan, on Oct. 26, 1995. Paratype $\sigma^{\top}$ attracted to a light source emitted by a vending machine set at the shore of Lake Biwa, Uchiidehama, Ohtsu-Shi, Shiga Pref., Japan, on Oct. 25, 1995. Paratype $\sigma^{7}$ collected by sweeping at the shore of Lake Biwa, Kitafunaki, Adogawa-Cho, 
Takashima-Gun, Shiga Pref., Japan, on May 18, 1995.

Discussion: This species belongs to the genus Harnischia Kieffer because both dorsal and ventral appendages are highly reduced and gonostylus is almost parallelsided and without keel. It is somewhat related to $H$. japonica Hashimoto in general structure of hypopygium, but it clearly differs from the latter in that the anal point is much longer and stouter and the gonostylus is shorter and almost straight (See Hashimoto, 1984). It is also related to $H$. inaefeus Sasa in general structure of hypopygium, but it clearly differs from the latter in that the gonostylus is almost parallel-sided and the anal point is slender (See Sasa, Kitami and Suzuki, 2001).

\section{Polypedilum akipulcher sp. nov.}

Male $(n=1)$

Coloration (in specimen mounted in gum-chloral): Head yellowish. Pedicel pale brown. Antennal shaft and plume brown. Palps pale yellow. Scutal background hyaline. Scutal stripes yellowish, indistinguishable. Scutellum yellowish. Postnotum brownish-yellow. Halteres pale yellow. All legs pale yellow. Abdomen yellowish, distally slightly darkened. Hypopygium brownish-yellow.

Structure: AR 1.03. SO 11. Eyes with strong dorsomedial projections, ER 0.34. CL 14. DM 10. DL 12-13. SA 4. SC 14. SQ 6-9. Wing as in Fig. 4A. Wing membrane without any cloudy marks. Anal lobe slightly developed. Costa not produced beyond the tip of $R_{4+5}$. $R_{2+3}$ running separately from both $R_{1}$ and $R_{4+5}$ and ending close to the tip of $R_{1} . R_{4+5}$ ending above the tip of $\mathrm{M}$. FCu well beyond RM. $\mathrm{LR}_{2}$ 0.53. $\mathrm{LR}_{3}$ 0.67. $\mathrm{BR}_{2}$ 4.6. $\mathrm{BR}_{3}$ 6.3. Front tibia with a rounded terminal scale. Middle and hind tibiae with two terminal combs; one with a spur, the other unarmed. Pulvilli well developed. Hypopygium as in Fig. 4B. Anal point long, lobust, distally tapered and apically pointed. Dorsal appendage sickle- shaped, almost straight and apically abruptly curved and with two basal setae, and with a lateral seta, inserted at apical $1 / 5$. Ventral appendage short and robust, with strong bristles on apical $1 / 3$. Gonostylus short, gradually tapering to apex, with its inner margin straight and with long setae along inner margin.

Size: BL $2.65 \mathrm{~mm}$ WL $1.42 \mathrm{~mm}$.

Type material: Holotype $\sigma^{x}$ attracted to a light trap set at the shore of the Ohta River, Yoshiwa-Mura, Saeki-Gun, Hiroshima Pref., Japan, on Aug. 21, 1996.

Discussion: This species is somewhat related to $P$. okipallidum SASA in coloration and general structure of hypopygium, but it clearly differs from the latter in that the gonostylus is by far shorter, the ventral appendege is also shorter and the lateral seta of dorsal appendage is inserted at apical 1/5 (See Sasa, 1990).

Tanytarsus hajifissus sp. nov.

Male $(n=1)$

Coloration (in specimen mounted in gum-chloral): Head brown. Pedicel dark brown. Antennal shaft and plume brown. Palps pale brown. Scutal background yellowish-brown. Scutal stripes dark brown, conspicuous. Scutellum yellowishbrown. Postnotum dark brown. Halteres pale. Legs almost uniformly yellowishbrown; front tarsi brownish. Abdominal tergites yellowish-brown. Hypopygium brown. Tergites II-IV each medially with a longitudinal broad dark spot.

Structure: AR 1.02. SO 11. Eyes with moderate dorsomedial projections, ER 0.7. CL 15. DM 13. DL 6-7. SA 2. SC 5. SQ 0. Wing as in Fig. 5A. Wing membrane with macrotrichia on distal half; dense only on a distal portion. Anal lobe only weakly developed, almost obtuse. Costa not produced beyond the tip of $R_{4+5} \cdot R_{2+3}$ running separately from both $R_{1}$ and $R_{4+5}$ and ending close to the tip of $R_{1} \cdot R_{4+5}$ ending distal to the tip of $\mathrm{Cu}_{1}$. $\mathrm{FCu}$ well beyond RM. $\mathrm{LR}_{1}$ 2.00. $\mathrm{LR}_{2}$ 0.55. $\mathrm{LR}_{3} 0.71$. $\mathrm{TR}_{1}$ 0.28. $\mathrm{BR}_{1}$ 3.6. $\mathrm{BR}_{2}$ 3.9. $\mathrm{BR}_{3}$ 4.1. Front tibia with a terminal spine. Middle and 

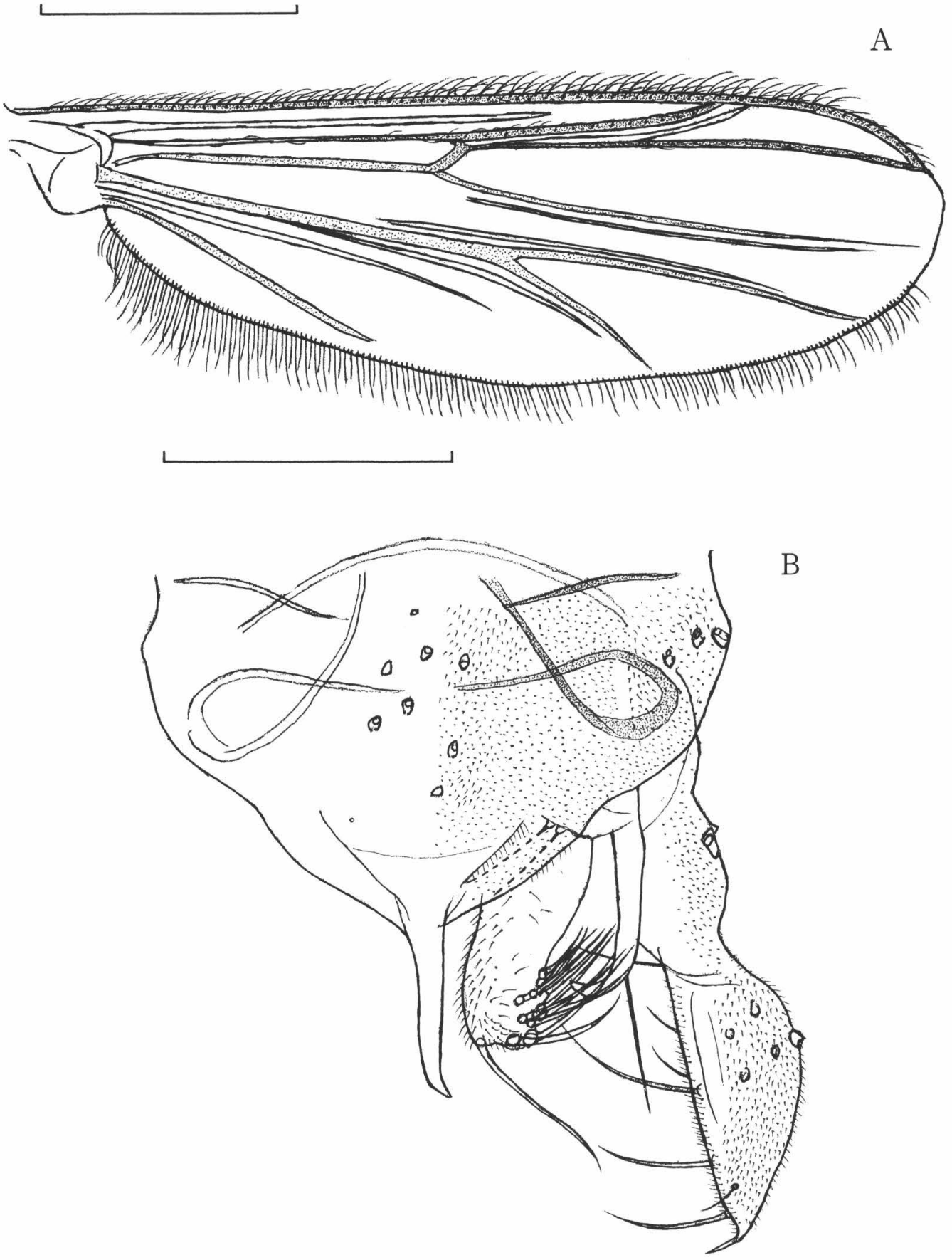

Fig. 4. Polypedilum akipulcher sp. nov. Male. A, wing. Scale: $0.5 \mathrm{~mm}$; B, hypopygium. Scale: $0.1 \mathrm{~mm}$.

hind tibiae with two terminal combs; each with a longish spur. Pulvilli vestigial. Hypopygium as in Fig. 5B. Ninth tergite bands widely separated in the middle. Anal point wide, triangular and distally tapered, and with lateral ridges on both sides and a row of spine clusters. Dorsal appendage oval, with rounded inner margin, but having a distal finger-like process and with a fissure between them. It with 2 


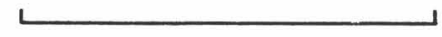

A
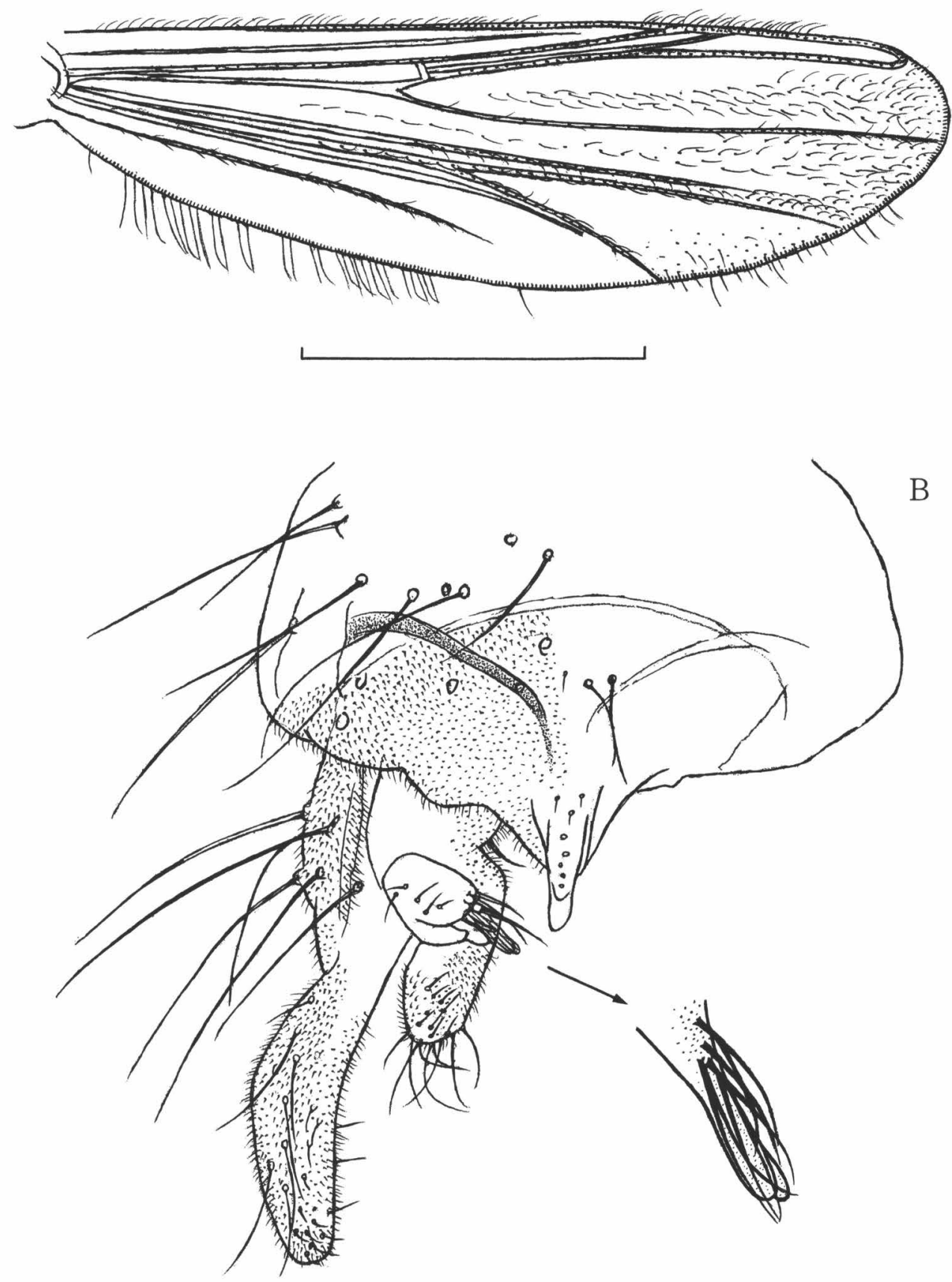

Fig. 5. Tanytarsus hajifissus sp. nov. Male. A, wing. Scale: $1 \mathrm{~mm}$; B, hypopygium. Scale: $0.2 \mathrm{~mm}$.

strong setae on inner margin and 4 dorsal setae, and ventrally with a strong seta, arising from a conspicuous basal tubercle. Digitus long and far beyond the inner margin of dorsal appendage. Ventral appendage robust, with rounded apex and with about 15 setae distributed on distal $1 / 3$. Median appendage short, not reach- 
ing the apex of ventral appendage, with a few leaf-like processes and several simple setae. Gonostylus long, widest at about distal $1 / 3$ and with curved inner margin.

Size: BL $3.80 \mathrm{~mm}$ WL $2.30 \mathrm{~mm}$.

Type material: Holotype $\sigma^{\pi}$ emerged from a bottom sample collected from the Gono River, Yachiyo-Cho, Takada-Gun, Hiroshima Pref., Japan, on Mar. 10, 1998.

Discussion: This species is somewhat related to $T$. tamagoto $i$ SASA and $T$. holochloris EDWARDS in general structure of hypopygium, but it clearly differs from the latter two species in that the inner margin of dorsal appendgae is rounded and without any processes and the body coloration is brownish (See Sasa, 1983; Pinder, 1978).

\section{REFERENCES}

Hashimoto, H. 1984. A new species of Harnischia (Diptera, Chironomidae) from Japan. Konchu, 52: 262-265.

Pinder, L. C. V. 1978. A key to adult males of British Chironomidae. Freshwater Biol. Assoc. Sci. Pull., No. 37: 1-169, Figs. 189.

Sasa, M. 1983. Studies on chironomid midges of the Tama River. Part 5. An observation on the distribution of Chironominae along the main stream in June, with description of 15 new species. Res. Rep.
Natl. Inst. Environ. Stud., 43: 1-67.

Sasa, M. 1985. Studies on the chironomids collected from lakes in southern Kyushu (Diptera, Chironomidae). Res. Rep. Natl. Inst. Environ. Stud., 83: 25-99.

Sasa, M. 1990. Studies on the chironomid midges (Diptera, Chironomidae) of the Nansei Island, southern Japan. Jpn. J. Exp. Med., 60: 111-165.

Sasa, M. and Kikuchi, M. 1995. Chironomidae of Japan. 333pp., Univ. Tokyo Press, Tokyo.

Sasa, M., Kitami, K. and Suzuki, H. 2001. Additional studies on the chironomid midges collected on the shore of Lake Inawashiro. 37 pp., Noguchi Hideyo Kinenkan 2, Fukushima.

Sasa, M. and Okazawa, T. 1992. Some characteristius of nature conservation within the chief rivers in Toyama Prefecture (The upper reach of Kurobe River). Studies on the chironomid midges of TogaMura, Toyama. Pt. 2. The subfamily Orthocladiinae. Res. Rep. Toyama Pref. Environ. Poll. Res. Center, 1992: 92-204.

Sasa, M., Yasuno, M., Ito, M. and Kikuchi, T. 1980. Studies on chironomid midges of the Tama River. Part 1. The distribution of chironomid species in a tributary in relation to the degree of pollution with sewage water. Res. Rep. Natl. Inst. Environ. Stud., 13: $1-8$.

Wiederholm, T. E. 1989. Chironomidae of the Holarctic region. Keys and diagnoses. Part 3-Adult males. Entomal. Scand. Suppl., 34: 1-532. 